\title{
Research on free flying of high speed aircraft without control
}

Aijun Zhou ${ }^{1, a}$, Haibo Wang ${ }^{1}$, Junbo Chu ${ }^{2}$ Tianwei $\mathrm{Li}^{1}$ and Guoqiang Liang ${ }^{3}$

${ }^{1}$ Department of navigation, Dalian Naval Academy Dalian, 116018, China

${ }^{2}$ Department of missile, Dalian Naval Academy Dalian, 116018, China

${ }^{3}$ Department of control engineering, Naval aeronautical and astronautical University Yantai, 264001, China

azajwxy@163.com

Keywords: aircraft; stability; control; free flying; numerical simulation

Abstract. The research is based on a kind of pitch channel hypersonic aircraft model built is released by USA air force, adopting the digital simulation to verify the basic free flight state preliminarily. The difference of the stability and divergent could get observation through the simulation result between hypersonic aircraft's attitude and attack angle and the traditional low supersonic aircraft. The research is aimed at evaluate the rationality of models, and do the preliminary analysis of the dynamic characteristics of hypersonic aircraft.

\section{Introduction}

Model built is the basic issue all over the research of hypersonic aircraft, and the accurate model is quite difficult ${ }^{[1-7]}$. Now, the Wind tunnel experiments try to obtain the experiment data as much as possible for typical feature points, and the experimental data is fitted into mathematical model with some errors at last. At the same time, the errors are also existed in the experimental data and the real flight. So modeling of hypersonic aircraft is very hard ${ }^{[8-12]}$. Even though, the domestic scholars are still do this research. The domestic model is classified as usual. USA published some kinds of typical models of hypersonic aircraft, but the effectiveness and accuracy of parameters need the further verified by the experiment.

\section{Model Description}

Considering the elastic shape structure, a kind of pitch channel hypersonic aircraft model built according to Lagrange equation is released by USA air force as followed:

$$
\begin{array}{r}
\dot{V}=\frac{T \cos \alpha-D}{m}-g \sin \gamma \\
\dot{\phi}=-2 \varsigma \omega_{n} \phi-\omega_{n}^{2} \phi+\omega_{n}^{2} \phi_{c} \\
\dot{\gamma}=\frac{L+T \sin \alpha}{m V}-\frac{g \cos \gamma}{V} \\
\dot{\alpha}=q-\dot{\gamma} \\
\dot{q}=\frac{M}{I} \\
\dot{h}=V \sin \gamma \\
\ddot{\eta}_{i}=-2 \varepsilon_{m} \omega_{m i} \dot{\eta}_{i}-\omega_{m i}^{2} \eta_{i}+N_{i}
\end{array}
$$

Where

$$
T=\bar{q} s\left(C_{T \phi} \phi+C_{T}+C_{T}^{\eta} \eta\right), D=\bar{q} S C_{D}
$$




$$
\begin{gathered}
N_{i}^{\eta}=\left[N_{i}^{\eta_{1}}, 0, N_{i}^{\eta_{2}}, 0, N_{i}^{\eta_{3}}, 0\right] \\
C_{j}^{\eta}=\left[C_{j}^{\eta_{1}}, 0, C_{j}^{\eta_{2}}, 0, C_{j}^{\eta_{3}}, 0\right], j=T, M, L, D \\
C_{T}^{\eta} \eta=6.783 * 10^{-2} \eta_{1}+3.226 * 10^{-2} \eta_{2}+8.635 * 10^{-2} \eta_{3}
\end{gathered}
$$

And $V$ is speed, $\gamma$ is the speed angle, $\alpha$ is attack angle, $Q$ is the attitude angle speed, $h$ is the height. $\phi$ is the oil supplying factor, $\delta_{c}$ is the duck wing and $\delta_{e}$ is the lift rudder.

\section{Simulation settings of free flying}

In order to testify the rightness of the model of hypersonic aircraft, choose a initial height as $h_{0}=85000 * 0.3048$, initial speed as $V_{0}=7846 * 0.3048$, initial attack angle as $\alpha_{0}=0.0174$, and other initial state as: $\gamma_{0}=0, q_{0}=0, \eta_{10}=0.4588 * 0.3048 * 14.59, \eta_{20}=-0.08726 * 0.3048 * 14.59$, $\eta_{30}=-0.03671 * 0.3048 * 14.59$, and set the oil supplying law as constant as $\phi=\phi_{c}=0.1$, and choose the control as $\delta_{c}=\delta_{e}=0$, then the free flying test can be done by numerical simulation and simulation time is set as 0.2 second.

\section{Numerical Simulation and result analysis}

With above initial conditions, the simulation results can be shown as below figures.

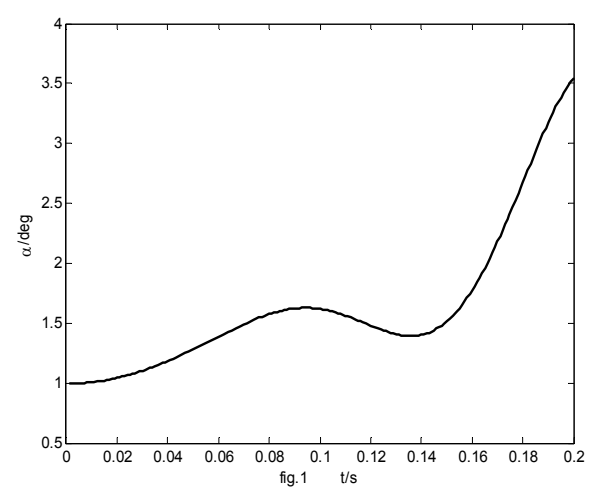

Fig 1 The curve of attack angle

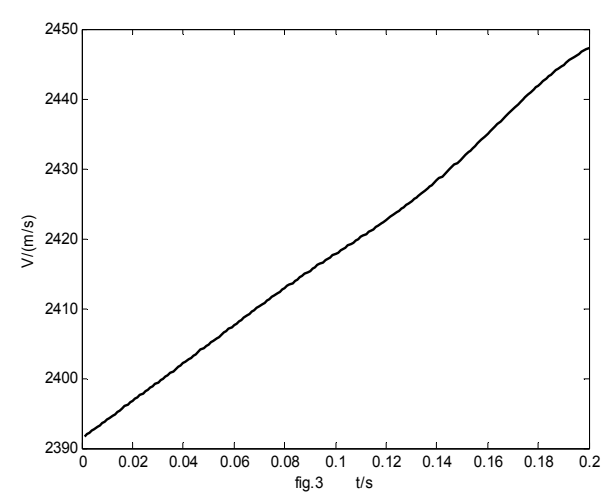

Fig 3 The curve of speed

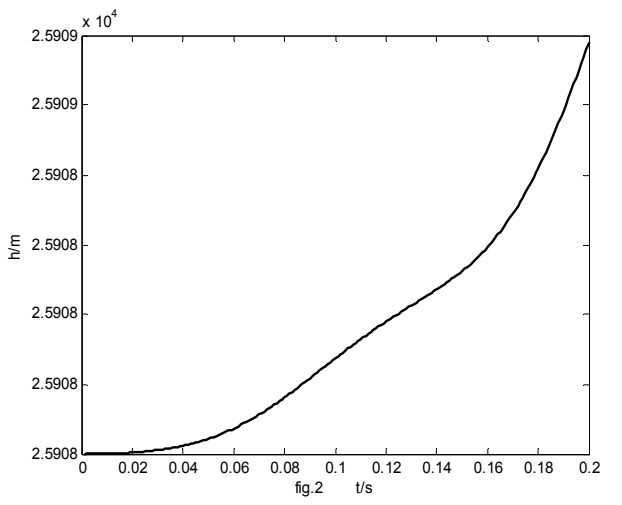

Fig 2 The curve of the height

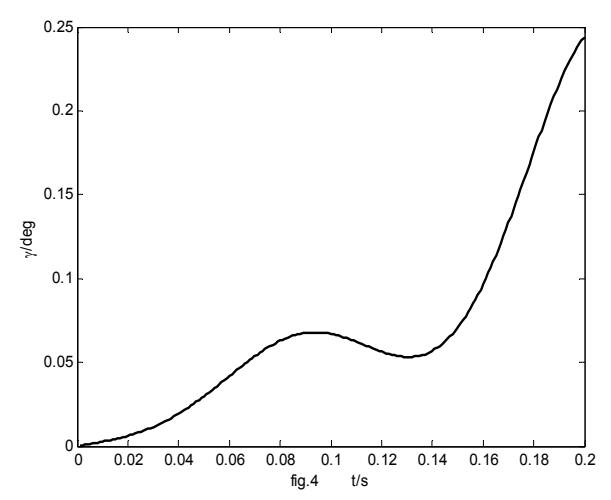

Fig 4 The curve of speed angle 


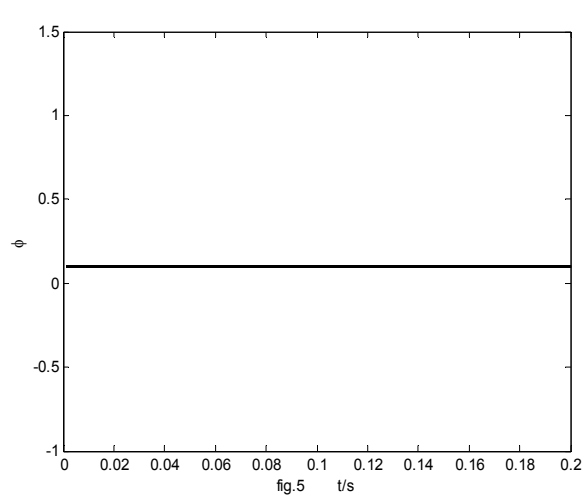

Fig 5 The curve of oil supplying factor

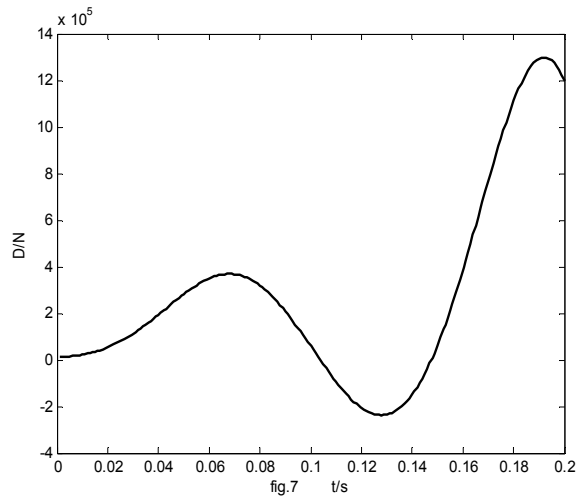

Fig 7 The curve of resistance

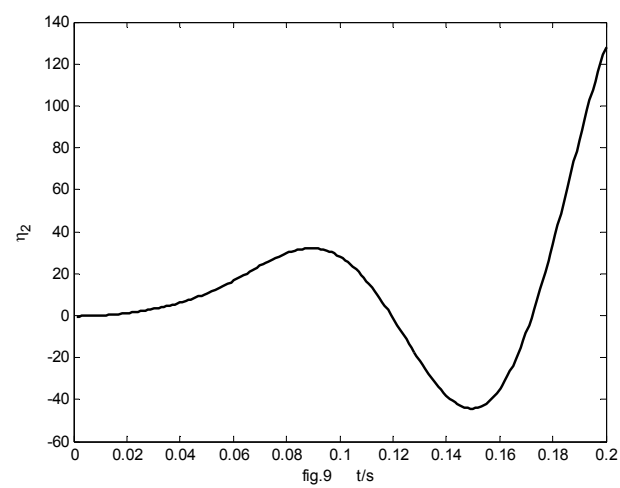

Fig 9 The state of second elastic shape

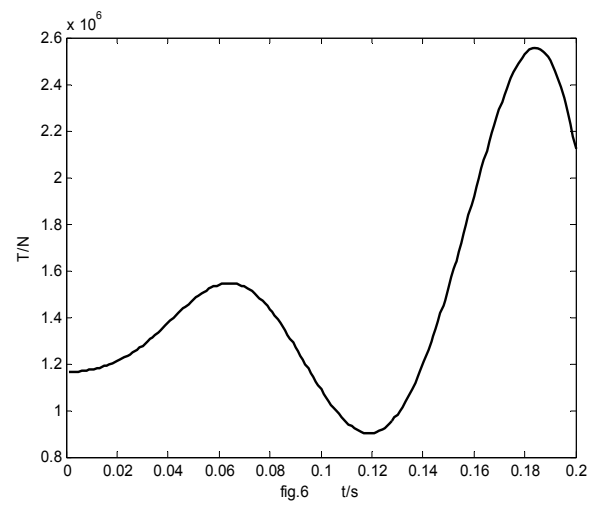

Fig 6 The curve of thrust

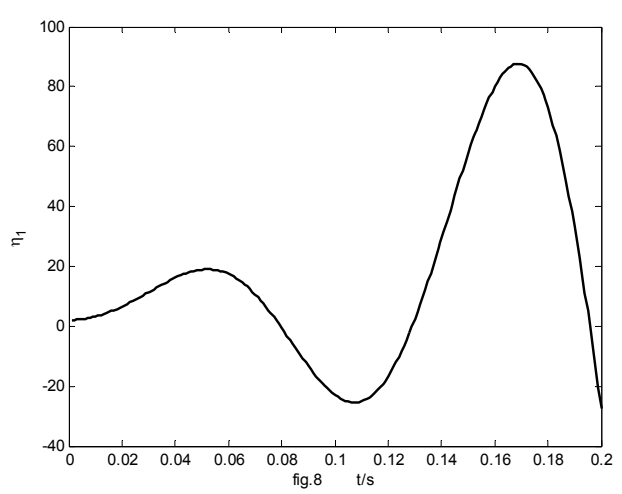

Fig 8 The state of first elastic shape

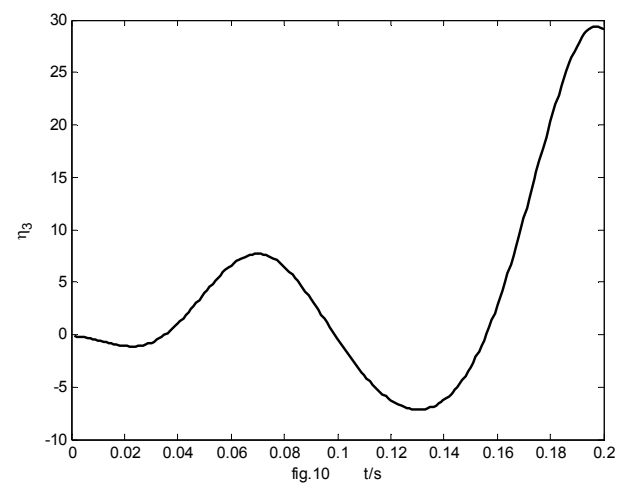

Fig 10 The state of third elastic shape

The free flying without control is stability basically on $0.2 \mathrm{~s}$ through the curves above. The hypersonic aircraft is also stability, if the non-control flying time is prolong to $0.5 \mathrm{~s}$. But the attack angle will be overlarge, leading to the system instability. The free flying without control's stability at $0.5 \mathrm{~s}$ can verify the rationality of hypersonic aircraft model enough, also it gain the point of verifying the model.

\section{Conclusion}

This paper obtain the whole pitch channel hypersonic aircraft model considering the affect of the elastic shape structure and make use of dynamic model of hypersonic aircraft engine. This model refers to a kind of pitch channel hypersonic aircraft model built according to Lagrange equation is released by USA air force, and fitting the missing parameter' data through the experience. At last, the simulation program is established to verify the rationality of hypersonic aircraft model, and get the result of non-control free flying stability at $0.5 \mathrm{~s}$. The hypersonic aircraft model is too hard to control or the hidden problem will be existed in the model if the flying time is too short. The model maybe be consider too simple to measure the fast changing with time of the model, if free flying time without control exceeds $0.5 \mathrm{~s}$. 


\section{References}

[1]Wang J L, Sundararajan N. A nonlinear flight controller design for aircraft[J].Control Eng.Practice, 1995, 3(6): 813-825.

[2]A. E. Finzi, M. Lavagna, A. Di Gregorio, Atmospheric re-entry trajectory tracking and control for an unmanned space vehicle with a Lyapunov approach [A], In: AIAA Guidance, Navigation, and Control Conference and Exhibit [C], Austin: AIAA, 2003-5441

[3]Sigthorsson D O, Serranni, Yurkovich S, et a1. Tracking control for an overactuated hypersonic air-breathing vehicle with steady state constraints, In: AIA A Guidance, Navigation, and Control Conference and Exhibit,Keystone, USA, AIAA 2006-6558: 1-17.

[4]Vaddi S S, Sengupta P. Controller design for hypersonic vehicles accommodating nonlinear state and control constraints, In: AIAA Guidance, Navigation, and Control Conference Chicago, USA, AIAA 2009-6286: 1-19.

[5] Reiman S E, Dillon C H, Lee H P, et a1 . Robust adaptive reconfigumble control for ahypersonic cruise vehicle, In: AIA A Guidance,Navigation, and Control Conference, Chicago, USA, AIA A 2009-6185: 1. 10 .

[6]Christopher I. Marrison. synthesis of robust control systems for a hypersonic aircraft decision and contro1. IEEE, 1994。4:3324-3329

[7]E. mooij. 1inear quadratic regulator reentry control-performance assessment using a taguchi approach. AIAA, international space planes and hypersonic systems and technologies conference. 1998: 665-677.

[8]Kevin. P. Groves, Andrea. Serranti, Stephen. Yurkovich. Anti-Windup Control for an Air-breathing Hypersonic Vehicle Model. AIAA, 2006-6557: 1-14.

[9]Gregory I M, Mcminn J D and Shaughnessy J D. Hypersonic vehicle control law development using $\infty \mathrm{H}$ and $\mu$-synthesis [R]. NASA TM-4562, 1994.

[10]Lohsoonthorn P, Jonckheere E and Dalzell S. Eigenstructure vs constrained $\infty \mathrm{H}$ design for hypersonic winged cone [J]. Journal of Guidance, Control, and Dynamics, 2001, 24(4): 648-658.

[11]Marrison C I and Stengel R F. Design of robust control systems for a hypersonic aircraft [J],Journal of guidance, control and dynamics, 1998, 21(1): 58-63.

[12]Heller M, Holzapfel F and Sachs G. Robust lateral control of hypersonic vehicles [A]. In: AIAA Guidance, Navigation, and Control Conference and Exhibit [C]. Denver, CO, AIAA 2000-4248. 